\title{
The Ocean supplies more EPA and DHA than we can use
}

Oléagineux, Corps Gras, Lipides. Volume 11, Numéro 2, 112-5, MARS/AVRIL 2004, Sources

\author{
Auteur(s) : R.G. ACKMAN \\ Professor Emeritus, Department of Food Science and Technology, Dalhousie University, Box 1000, \\ Halifax, Nova Scotia, B3J 2X4, Canada \\ Tel.: 9024946030
}

Fax: 9024200219

<robert.ackman@dal.ca>

Summary : Nutraceutical is a modern marketing term and a source of much confusion, nowhere more obviously than in the field of polyunsaturated fatty acids. The world supply of vegetable oils includes an abundance of an unsaturated and omega 6 (or n-6) C18 fatty acid, linoleic, which has been declared for decades as "essential" for elongation to the C20 trienoic and tetraenoic n- 6 fatty acids vital to the functioning of our body systems. It also keeps most of the vegetable oils liquid or semi-liquid. A frequent minor partner fatty acid is the C18 omega 3 fatty acid alpha-linolenic (18:3n3) which was sensitive to oxidation and therefore a nuisance in salad and frying oils and margarines. Wherever possible, it was reduced or eliminated. Within the last two decades we have realized that our conversion of 18:3n-3 to the "truly essential" 20:5n-3 (EPA) and especially 22:6n-3 (DHA), via 22:5n-3 (DPA), is poor, and we have depended on DHA from eggs and certain animal meats. Fish and shellfish for both were the most useful sources in our diets but were not recognized officially until 1996. Then U.K. Report No. 46 recommended eating fish twice a week, one being oily. More recently the American Heart Association has followed suit. This review shows how the microalgae of the oceans produce and concentrate generous supplies of these two highly desirable dietary fatty acids available from a truly "functional" foodi

Keywords : omega 3, photosynthesis, microalgae

\section{ARTICLE}

Among the peculiar statements or assertions recently made promoting omega 3 nutrition and nutraceutical products two are worth discussing. One is that the menhaden oil used in a new margarine type in the USA is "organic". This can only be compared with the term "organic farming" which has become to refer to foodstuffs produced without fertilizers or chemical pesticides. A second claim of note is that it is a supplemental source of DHA. It can also be described as "vegetarian". In fact the well-known infant formula Martek Biosciences Corp. product [1] for DHA supplementation of infant formulas is derived from a cultured single-celled Crypthecodinium cohnii alga. It is interesting that Martek are taking legal action against a competing product advertised as "vegetarian" by Nutrinova Inc. 
The application of such products during pregnancy and infant nursing has recently been included in a review in this journal by J.-M. Bourre [2]. The second is that although I have been associated with marine and freshwater fish lipids for many years, it was only a few years ago that I began to question the facile and neatly drawn conversions of alpha-linolenic acid (ALA, 18:3n-3) to EPA and DHA in fish as well as other marine organisms. This was stimulated by the recent critical works published on humans achieving the same conversion but only to a limited degree $[3,4]$. It now may seem strange that there was a prolonged struggle to get ALA the status of an "essential" fatty acid [5]. Originally this was cautiously accepted but primarily because it apparently could not be biosynthesized by animals. ALA as "essential" was only tolerated in nutrition because it might have a role in keeping skin in good health. In contrast the $n-6$ linoleic acid (LA, 18:2n-6) was enthusiastically stuffed into our diets from the 1950s on in attempts to reduce serum cholesterol $[6,7]$ and that time not because of any other obvious clinical need except for the clotting aid thromboxane B2. Now we know that this was adding to the pre-existing n-6/n-3 imbalance in our diets with dubious consequences.

In respect to EPA (20:5n-3) and DHA (22:6n-3) they were simply ignored as they were presumed to be easily made by the body from ALA. In an attempt to promote our understanding of the "essentiality" of three different chain lengths, S. Cunnane coined the phrase "conditionally essential" for both LA and ALA [8]. It has however not been widely accepted. We have in fact only lately sorted out reports showing that only a small percentage of the ALA consumed daily is utilized by the human body [9], and that the reason for DHA being truly essential is probably the very low activity of the delta- 6 desaturase step in the Sprecher shunt necessary to produce DHA $[10,11]$. This introduces a new ethylenic bond in $24: 5 n-3$ to give $24: 6 n-3$ which is then chain-shortened to $22: 6 n-3$. This route can apply along with dietary sources as the origin of the DHA normally found in human milk [11] and is included in the most recent review of the essentiality of DHA in humans [12].

Before closing the health/biomedical situation with apologies to Dr. Bourre for duplicating some of his recent papers [2], it should be noted that table 1 provides a partial listing of the $n-3$ fatty acids commonly found in marine oils. In an attempt to produce the highest possible numbers for labelling of health-related products to overawe consumers [13], two less well-known n-3 polyunsaturated fatty acids may be included. These are obvious in the phytoplankton and zooplankton in Table 1 and are found in our edible marine products, being respectively $18: 4 n-3$ and $18: 5 n-3$. Although only traces of $18: 5 n-3$ can be discerned in many fish oils, $1-3 \%$ of $18: 4 n-3$ is usually there. The $18: 5 n-3$ is readily converted to $18: 4 n-3$ in fish cells [14], and the 18:4n-3 itself is useful in humans [4]. The interconversion of the three C20-C22 polyunsaturated $n-3$ fatty acids EPA, DPA and DHA has been known for years and is of special interest in tissues such as the endothelium of blood vessels [15]. It should be noted here that the marine world considers that only the $n-3$ docosapentaenoic acid $(22: 5 n-3)$ is of interest and common at the $1-2 \%$ level in all fish oils, while the alternative DPA isomer $22: 5 n-6$ is present only in traces compared to the $22: 5 n-3$. 
Table 1. Proportions* of recovered unsaturated fatty acids in an experiment where mixed phytoplankton were grazed on by copepods in a natural enviornment and subsequently the copepods were the food of herring larvae**. A partial single analysis of northern Atlantic herring oil is given for comparison.

\begin{tabular}{|c|c|c|c|c|}
\hline $\begin{array}{l}\text { Fatty acid } \\
\text { total lipid }\end{array}$ & $\begin{array}{l}\text { Phytoplankton, total } \\
\text { lipid }\end{array}$ & $\begin{array}{l}\text { Zooplankton, total } \\
\text { lipid }\end{array}$ & $\begin{array}{l}\text { Herring larvae, } \\
\text { triacylglycerols }\end{array}$ & $\begin{array}{l}\text { North Sea } \\
\text { herring oil }\end{array}$ \\
\hline $16: 1 n-7$ & 13 & 4 & 5 & 7 \\
\hline $18: 1 n-9$ & 3 & 4 & 5 & 10 \\
\hline $18: 2 n-6$ & 2 & 2 & 2 & 1 \\
\hline $18: 3 n-3$ & 2 & 2 & 3 & 2 \\
\hline $18: 4 n-3$ & 10 & 6 & 17 & 3 \\
\hline $18: 5 n-3$ & 8 & 1 & 1 & \\
\hline $20: 4 n-6$ & Trace & 1 & Trace & Trace \\
\hline $20: 5 n-3$ & 13 & 18 & 15 & 7 \\
\hline $22: 5 n-3$ & Trace & 1 & 1 & 1 \\
\hline $22: 6 n-3$ & 15 & 24 & 20 & 7 \\
\hline
\end{tabular}

*w/w percent; ** From Fraser et al. [23].

The results of my own evaluation of the origins of EPA and DHA, shown in figure 1, first appeared in an article promoting salmon as a source of DHA [16]. In this brief review not all arguments can be presented, but in a more extensive review D.R.Tocher has come to similar conclusions [17.

There is much variation in the fatty acids of phytoplankton (microalgae), and a recent paper in this publication tabulated the principal fatty acids of five microalgae popular in aquaculture [18]. Many other authors have conducted similar studies in connection with aquaculture. What is not clear from these studies is that there are often high degrees of selectivity in how small marine animals consume the most desirable microalgae from those available, perhaps primarily on the basis of relative size (figure 2). The immobile molluscan filter-feeders have to make do with whatever food is delivered by the ocean currents. Some of this can be detritus, particles including dead phytoplankton, or remains of dead zooplankton or their feces, all with or without coating of bacteria that can also be utilized for food [19]. From phytoplankton they can also accumulate toxins deadly to humans [20], but these animals have to have membranes with whatever are to them "essential" fatty acids [21], including the long-chain polyunsaturates. There may be an insufficient supply but apparently they can utilize a delta-5 desaturase operating during the biosynthesis of monounsaturated C20 fatty acids to fill in the orderly rows of phospholipids in membranes with 5,11-20:2. Concurrently or subsequently they may 
be elongating these to $\mathrm{C} 22$ if necessary, generally to 7,13-22:2 [22].

Fraser et al. [23] have reported on a laboratory-type food chain conducted in a floating open-top plastic cylinder in a Scottish Loch. Filled with filtered seawater, zooplankton suitable as food for larval herring were introduced and later the predator on the zooplankton, newly hatched herring larvae. There were 13 major species of phytoplankton initially present to provide a good assortment of fatty acids when pooled from total lipids with the results shown in table 1.

Excepting for the surprising accumulation of $18: 4 n-3$, the herring larva unsaturated fatty acids in the triacylglycerols already resemble that of the composition of the oil from mature North sea herring [24]. Another difference of note however is the absence of more than $1 \% 20: 1$ and 22:1, fatty acids produced from the alcohols of copepods [25], that could make up 35\% of the fatty acids in this particular type of oceanic herring oil [24]. The larval herring present had been feeding for 28 days after hatching and may have used up most of the initial egg lipids during the initial 4-8 days of the study [23], but 20:1 and 22:1 were virtually absent. The role of selective feeding at either the first or second stage of this experiment is discussed by the authors.

Menhaden oil, from a fish species directly consuming North Atlantic or Gulf of Mexico phytoplankton by filter feeding, also shows [24] only $1.3 \%$ each of $18: 2 n-6$ and $18: 3 n-3$, but $11 \%$ of $20: 5 n-3$ and $9 \%$ of 22:6n-3. These figures may represent those fatty acid proportions in the phytoplankton of their diet.

It was on the basis of many such findings that figure 1 was prepared. Although the simple disposal of the phytoplankton 18:2n-6 and 18:3n-3may be presumptuous, their absence as significant lipid components in many marine invertebrates should be noted. Green algae are the most likely phytoplankton species to show accumulation of 18:2n-6 but only modest amounts of its successor acid arachidonic (20:4n-6). Correspondingly the very long-chain EPA and DHA may be modest in green algae except in Cryptomonads [26]. These generalities are expressly applicable to the North Atlantic and North Pacific ecosytems. In the tropics the sunlit coral reefs have many organisms with more substantial accumulations of arachidonic acid than in the colder northern latitudes. Possibly this provides for a greater range of chemical signals in the water in such crowded communities. We do not often think of fatty acids as essential for this among humans! There are suspicions among oceanographers that major changes in ocean water distribution are pending, perhaps in hundreds of years instead of millennia. The distribution of fish populations may be seriously affected, but the importance of sources of omega 3 fatty acids is of concern. Australian and New Zealand scientists are participating in many similar studies [26, 27].

The invertebrates of figure 2 are often concentrated and localized by mixing of water masses, but certainly are one of the major biomasses in the world's oceans. The work of M.V. Bell and colleagues has shown that rainbow trout held in freshwater were capable of catabolizing much of the dietary labelled 18:3n-3 with very little conversion to DHA [28], and they have followed biosynthesis in various organs and tissues [29]. This latent route to EPA and DHA in the trout, which in the ocean would normally be plentifully supplied with EPA and DHA in the wild, is probably paralleled by the modern position of humans in their handling of the conversion of ALA to DHA. Whether the EPA and DHA situation of falling supplies of fish oil in fish aquaculture can be offset by partial introduction of vegetable oils remains to be seen. The regrettable aspect of the natural supply of these two truly essential fatty acids, EPA and DHA, is that over-harvesting of fish is rapidly 
becoming a scandal, and the generous supply of natural vegetable EPA and DHA in the oceans will be mostly wasted.

Some activists advocate fish oil capsules as safer than fish, and some suspect that hidden benefits such as selenium may give fish a nutritional edge over capsules. Both are equally satisfactory [30], Recommendations for fish consumption by the American Heart Association [31] are summarized in a very readable review from the U.K. [32]. Part of its title is "Fishing for a natural treatment"! The safety of cultured algal supplies of the necessary long-chain, highly unsaturated omega 3 fatty acids in our diets is assured [1,33,34]. Unfortunately activist groups are prone to push potential problems to the fore, and the media flourish on exaggerating their interpretations of scientific data. Some such newsletters are more trustworthy than others [35], and it is not for nothing that BMJ (British Medical Journal) recently devoted its entire cover to a simple but ironic message: "Trust me. I'm a website." This is a sad commentary on our efforts to promote a natural source of our two truly essential fatty acids.

\section{REFERENCES}

1. HAUMANN BF. Alternative sources for n-3 fatty acids. Inform 1998; 9: 1108-16.

2. BOURRE JM. Relations entre acides gras oméga 3, oméga 9, structures des fonctions du cerveau. Le point sur les dernières données. Le coût financier alimentaire des oméga 3. OCL 2003; 10: 165-74.

3. BURDGE GL, JONES AE, WOOTTON SA. Eicosapentaenoic and docosapentaenoic acids are the principal products of $\alpha$-linolenic acid metabolism in young men. Br J Nutr 2002; 88: 355-63.

4. JAMES MR, URSIN VM, CLELAND LG. Metabolism of stearidonic acid in human subjects: comparison with the metabolism of other n-3 fatty acids. Am J Clin Nutr 2003; 77: 1140-5.

5. HOLMAN RT. The slow discovery of the importance of T3 essential fatty acids in human health. $J$ Nutr 1998; 128: 427S-33S.

6. VOSS E. Linoleic acid "vitamin F6", 2003.

7. NELSON GJ. Effects of dietary fatty acids on lipid metabolism. In: CHOW CK, ed. Fatty acids and their health implications. Marcel Dekker, New York, 2000; 481-516.

8. CUNNANE SC. Recent studies on the synthesis, $\beta$-oxidation, and deficiency of linoleate and alphalinolenate: are essential fatty acids more aptly named indispensable or conditionally dispensable fatty acids? Can J Physiol Pharmacol 1996; 74: 629-39.

9. INNIS SM, ELIAS SL. Intakes of essential n- 6 and n-3 polyunsaturated fatty acids among pregnant Canadian women. Am J Clin Nutr 2003; 77: 473-8.

10. INNIS SM, DYER RA. Brain astrocyte synthesis of docosahexaenoic acid from $n-3$ fatty acids is limited at the elongation of docosapentaenoic acid. J Lipid Res 2002; 43: 1529-36.

11. FRANCOIS CA, CONNOR SL, BOLEWICZ LC, CONNOR WE. Supplementing lactating women with flaxseed oil does not increase docosahexaenoic acid in their milk. Am J Clin Nutr 2003; 77: 226-33. 
12. MUSKIET FAJ, FOKKEMA R, SCHAAFSMA A, BOERSMA ER, CRAWFORD ML. Is docosahexaenoic acid (DHA) essential? Lessons from DHA status regulation, our ancient diet, epidemiology and randomized controlled trials. J Nutr 2004; 134: 183-6.

13. URALA N, ARVOLA A, LAHIEENMAKI L. Strength of health-related claims and their perceived advantage. Internat J Food Sci Technol 2003; 38: 815-26.

14. GHIONI C, PORTER AEA, SADLER IH, TOCHER DR, SARGENT JR. Cultured fish cells metabolize octadecapentaenoic acid (all - cis)3,6,9,12,15-18:5) to octadecatetraenoic acid (all - cis)6,9,12,1518:4) via its 2 - trans intermediate (trans)2, all - cis)6,9,12,15-18:5). Lipids 2001; 36: 145-52.

15. ACHARD F, BENISTANT D, LAGARDE M. Interconversions and distinct metabolic fate of eicosapentaenoic, docosapentaenoic and docosahexaenoic acids in bovine aortic endothelial cells. Biochim Biophys Acta 1995; 1255: 260-6.

16. ACKMAN RG. DHA: Can it benefit salmon marketing. J Aquatic Food Prod Technol 1966; 5 (4): 7 26.

17. TOCHER DR. Metabolism and functions of lipids and fatty acids in teleost fish. Rev Fish Sci 2003; 11: 107-84.

18. POISSON L, DEVOS M, PENCREAC'H G, EGAN F. Acides gras polyinsatués de microalgues: intérêts et développements actuels. OCL 2002; 9: 92-5.

19. BUDGE SM, PARRISH CC, MCKENZIE CH. Fatty acid composition of phytoplankton, settling particulate matter and sediments of a sheltered bivalve aquaculture site. Mar Chem 2001; 76: 285303.

20. AUNE T. Health effects associated with algal toxins from seafood. Arch Toxicol 1997; 19 (Suppl.): 389-97.

21. ARTS MT, ACKMAN RG, HOLUB BJ. "Essential fatty acids" in aquatic ecosystems: a crucial link between diet and human health and evolution. Can J Fish Aquat Sci 2001; 58: 122-37.

22. ACKMAN RG, HOOPER SN. Non-methylene-interrupted fatty acids in lipids of shallow-water marine invertebrates: A comparison of two mollusks (Littorina littorea and Lunatia triseriata) with the sand shrimp (Crangon septumspinosus). Comp Biochem Physiol 1973; 46B: 153-65.

23. FRASER AJ, SARGENT JR, GAMBLE JC, SEATON DD. Formation and transfer of fatty acids in an enclosed marine food chain comprising phytoplankton, zooplankton and herring (Clupea harengus $L$.) larvae. Mar Chem 1989; 27: 1-18.

24. ACKMAN RG. Fatty acid composition of fish oils. In: BARLOW SM, STANSBY ME, eds. Nutritional evolution of long-chain fatty acids in fish oil. Academic Press, London, 1982; 25-88.

25. RATNAYAKE WN, ACKMAN RG. Fatty alcohols in capelin, herring and mackerel oils and muscle lipids: II. A comparison of fatty acids from wax esters with those of triglycerides. Lipids 1979; 14: 80410. 
26. VOLKMAN JK, JEFFREY SW, NICHOLS PD, ROGER GI, GARLAND CD. Fatty acid and lipid composition of 10 species of microalgae used in mariculture. J Exp Mar Biol Ecol 1989; 128: 219-40.

27. HAREL M, LUND E, GAVASSO S, HERBER R, PLACE AR. Modulation of arachidonae and docosahexaenoate in Morone chrysops larvae tissues and the effect on growth and survival. Lipids 2000; 35: 1269-80.

28. BELL MV, DICK JR, PORTER AEA. Biosynthesis and tissue deposition of docosahexaenoic acid (22:6n-3) in rainbow trout (Oncorhynchus mykiss). Lipids 2001; 36: 1153-9.

29. BELL MV, DICK JR, PORTER AEA. Tissue deposition of n-3 FA pathway intermediates in the synthesis of DHA in rainbow trout (Oncorhynchus mykiss). Lipids 2003; 38: 925-31.

30. MAKI KC, DAVIDSON MH, DICKLIN MR, et al. Bioavailability of eicosapentaenoic and docosahexaenoic n-3 polyunsaturated fatty acids in salmon patties compared with capsules. J Food Sci 2003; 68: 761-4.

31. KRIS-ETHERTON PM, HARRIS WS, APPEL L. Fish consumption, fish oil, omega 3 fatty acids, and cardiovascular disease. Arterioscler Thromb Vasc Biol 2003; 23: e20-e30.

32. DIN JN, NEWBY DE, FLAPAN AD. Omega 3 fatty acids and cardiovascular disease-fishing for a natural treatment. Br Med J 2004; 328: 30-5.

33. CONQUER JA, HOLUB BJ. Supplementation with an algae source of docosahexaenoic acid increases $(n-3)$ fatty acid status and alters selected risk factor of heart disease in vegetarian subjects. J Nutr 1996; 126: 3032-9.

34. BEHRENS PW, KYLE DJ. Microalgae as a source of fatty acids. J Food Lipids 1996; 3: 259-72.

35. ANON. Harvard Health Letter January 2003. Harvard Health Publication. 


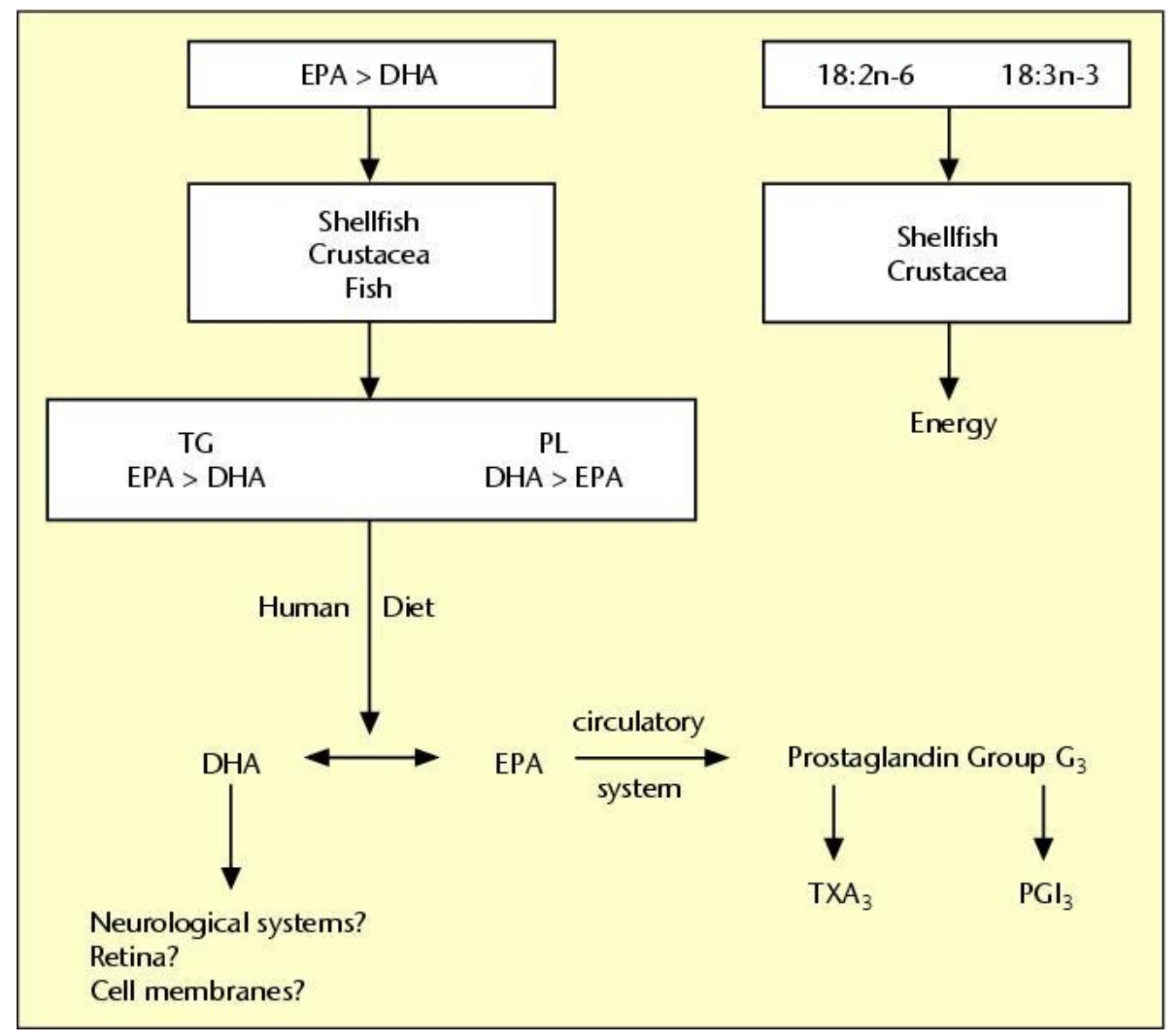

Figure 1. Schematic of the filtering and concentration steps that may apply to the polyunsaturated fatty acids photosynthesized in the oceans on the way to our food. 


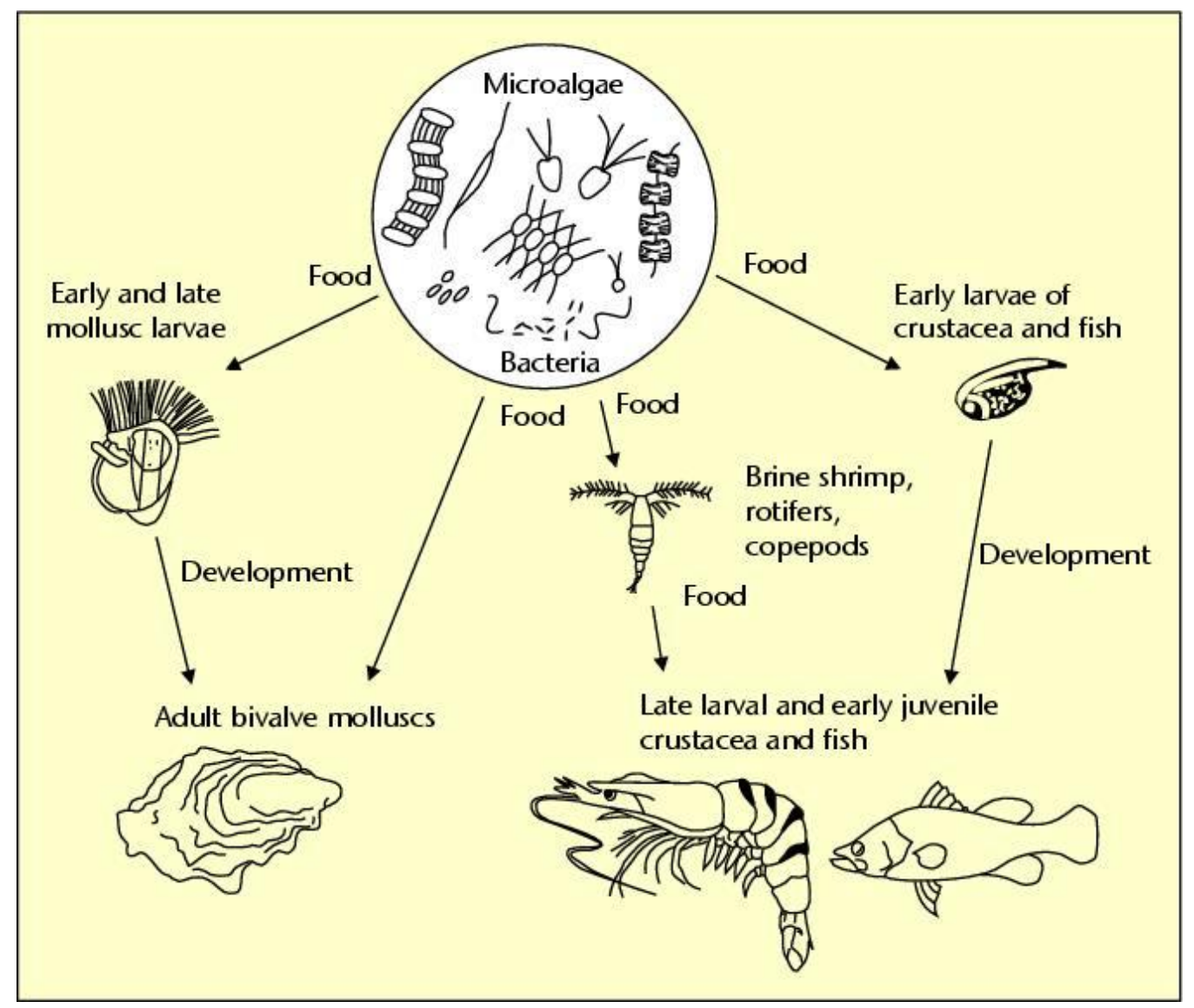

Figure 2. Schematic of the distribution routes for algal fatty acids from photosynthesis to our diets. Although humans are usually depicted at the top of the food pyramid numerous marine carnivores are omitted (e.g. squid, seabirds, seals and whales). 